\title{
Hepatitis C Antibody
}

National Cancer Institute

\section{Source}

National Cancer Institute. Hepatitis C Antibody. NCI Thesaurus. Code C116400.

An antibody produced by B-lymphocytes in response to hepatitis C virus infection. 